\title{
Prevalence and causes of musculoskeletal impairment in Mahabubnagar District, Telangana State, India: Results of a population based survey
}

Authors:

Tracey Smythe ${ }^{1}$, PhD candidate Infectious and Tropical Diseases, tracey.smythe@lshtm.ac.uk Islay Mactaggart ${ }^{1}$, Research Fellow Disability and Global Health, islay.mactaggart@Ishtm.ac.uk Hannah Kuper ${ }^{1}$, Professor of Epidemiology, hannah.kuper@lshtm.ac.uk GVS Murthy², Professor in Public Health Eye Care \& Disability, murthy.gvs@iiphh.org Christopher Lavy33, Professor of Orthopaedic and Tropical Surgery, chris.lavy@ndorms.ox.ac.uk Sarah Polack ${ }^{1}$, Associate Professor, sarah.polack@Ishtm.ac.uk

${ }^{1}$ International Centre for Evidence in Disability, London School of Hygiene \& Tropical Medicine ${ }^{2}$ Indian Institute of Public Health, Plot No \#1, A.N.V. Arcade, Amar Co-op Society, Kavuri Hills, Madhapur, Hyderabad, 500033, India

${ }^{3}$ Nuffield Department of Orthopaedics Rheumatology and Musculoskeletal Science, University of Oxford, UK.

Corresponding Author: Tracey Smythe International Centre for Evidence in Disability London School of Hygiene and Tropical Medicine Keppel Street London WC1E7HT

Tel: +44 (0) 2079588348

Target Journal: Transactions Royal Society Tropical Medicine

Word Count: Abstract 200 (limit 200); Text 3,493 (limit 3,500)

Tables: 5

Figures: 1

Funding: CBM 


\section{Abstract}

Background

Comparable epidemiological data on musculoskeletal impairments (MSI) is lacking. This study aimed to estimate the prevalence and causes of MSI in Telangana State, India.

\section{Method}

A population-based survey used probability proportionate to size and compact segment sampling to select fifty-one clusters of 80 individuals (all ages). Participants were screened using seven questions and any participant who screened positive underwent standardised examination by a physiotherapist for MSI presence, severity and diagnosis. Data were also collected on vision and hearing impairment, depression and self-reported difficulties with physical functioning.

\section{Results}

The prevalence of MSI was $19.6 \%$ (95\% Cl: $16.7-22.8 \%)$ and this increased with age. The majority $(81 \%)$ of $\mathrm{MSI}$ was classified as mild, $11 \%$ as moderate and $7 \%$ as severe. Over half $(57 \%)$ of MSI diagnoses were acquired non-traumatic causes, with degenerative joint disease being the most common. There was a high unmet need for physiotherapy services ( $3 \%$ attended vs $40 \%$ recommended). One fifth (21\%) of MSI cases also had at least one of vision $(10 \%)$ or hearing (11\%) impairment or depression (3\%)

\section{Conclusions}

MSI is common among persons living in Mahabubnagar District, particularly older adults.

These estimates can inform public health initiatives for the planning of health and rehabilitation services.

Keywords: prevalence, musculoskeletal impairment, India, survey, disability, 


\section{Introduction}

Musculoskeletal impairments (MSI) are a diverse group of conditions that can affect muscles, bones and joints, and are the leading contributor to global years lived with disability (1). It is well recognised that persons with disabilities are more likely to be exposed to determinants of poor health such as poverty, unemployment (2), social exclusion (3) and discrimination (4) compared to the rest of the population. Interventions are therefore needed both to treat MSI as well as to improve participation of people with MSI. Accurate data are needed to inform appropriate interventions and services (5), however measurement of functioning and disability has been limited by lack of consistent definitions and survey tools (4), particularly with respect to $\mathrm{MSI}$.

Assessing disability through self-reported functional limitations, as is used in the Washington Group (WG) Questions, is rapid and low cost. However, these methods are not designed to estimate the total number of people with disabilities who could benefit from specific health or rehabilitation interventions (5). Surveys using objective standardized clinical screening criteria to generate reliable and comparable estimates of prevalence, cause and severity of MSI are lacking because they rely on trained clinical specialists for assessment (6). These data are needed to understand and address the health and rehabilitation service needs of persons with MSI. The Rapid Assessment of Musculoskeletal Impairment (RAM) (6) is such a clinical screening tool developed to estimate prevalence and causes of MSI. Using a two step-process it includes screening questions to assess self-reported difficulties with the musculoskeletal system followed by a clinician-led examination. This survey tool has been used in surveys in Rwanda (7) and Cameroon (8),however, to date, such surveys have not been conducted in Asia and data on MSI is lacking in India.

Information is also lacking on the extent to which people with MSI also experience other impairments (e.g. hearing or vision). This information may be important to inform the planning of accessible and inclusive health and rehabilitation services. Another key gap is that the relationship between self-reported limitations in physical functioning (e.g. reported level of difficulty walking), which are relatively widely available, and the fewer data that report clinically assessed MSI is not well understood. Understanding this is important for informing and interpreting data from different assessment approaches in population surveys.

This study aims to estimate the prevalence and causes of MSI in Telangana State, India, through an all aged population-based survey. We also explore the relationship between selfreported functional limitations and clinically assessed MSI and between MSI and other impairments. 


\section{Materials and Methods}

\section{Survey population and sampling}

This study was undertaken in Mahabubnagar District, Telangana State in 2014 as part of a survey on disability that also collected data on vision, hearing and musculoskeletal impairment, depression and self-reported functional limitations (9). The required sample size was calculated to be 4,056 based on an expected MSI prevalence of $4 \%(7,10)$, precision of $20 \%, 95 \%$ confidence, a design effect of 1.5 and $20 \%$ non-response.

We used the 2011 census data for the sampling frame. A two-stage sampling procedure was used. First, 51 clusters of 80 individuals (all ages) were selected using probability proportionate to size sampling. Second, within clusters, households were selected through compact segment sampling. Maps were divided into segments of approximately 80 people and one segment was randomly selected. The enumerators visited all households sequentially in that segment until 80 people were included (although for logistical reasons, 4,125 people were enumerated).

Demographic details recorded included the name, age, sex and contact details of each household member. Household members were informed about the survey and invited to attend a clinic at a central location over the following two days. If an eligible person did not attend, the enumerators visited their home at least twice to encourage attendance. The survey team visited any eligible person who was unable to travel (e.g. due to mobility impairment) at their home at the end of the second day.

\section{Screening for musculoskeletal impairment}

The RAM survey was used to identify persons with mild, moderate or severe MSI that impact functioning (6). The RAM methodology comprises a two-stage approach: a self-reported screening tool followed by clinical assessment. The original RAM included 5 initial screening questions to assess MSI: a) difficulty using the musculoskeletal system ( 3 items), b) use of mobility aids ( 1 item) and c) whether the participant considered any body part to be missing or misshapen (1 item). We added an additional question on chronic back pain based on our experience in a previous study, which indicated the screening questions were not picking up people experiencing long-term debilitating back pain (8).

A physiotherapist examined any participant with a positive response to at least one screening question. The examination included a standardised observation of activities to assess functioning (e.g. walking, putting on a jacket) and examination of the affected area. Diagnoses categories for $\mathrm{MSI}$ included congenital, traumatic, infective, neurological, or 
acquired non-traumatic non-infective. The physiotherapist assigned a specific diagnosis within these categories with a maximum of two diagnoses per case. Aetiology was recorded where the timing and cause of the impairment was known. Based on these interviews and examinations, the participant was categorised by the physiotherapist as having mild, moderate or severe MSI in respect to the musculoskeletal system's ability to function. Lastly, participants were asked about treatment or rehabilitation that they had received for their impairment and physiotherapists made referral recommendations with consideration to the available services.

\section{Screening for vision, hearing impairment and depression}

Visual acuity (VA) was assessed using a tumbling 'E' chart with $6 / 18$ and $6 / 60$ size optotypes for participants aged $>5$ years. Vision Impairment was defined as presenting $V A<6 / 18$ in the better eye. For children aged $<2$ years, vision was assessed using the fix and follow method. For children aged 2-4 years, the child was asked to count or copy the number of fingers held up by a vision screener at 6 meters. Children who failed these tests were classified as having vision impairment.

Initial hearing screening was conducted through an otoacoustic emissions (OAE) hearing test. Participants who failed this test in both ears or for whom an OAE reading could not be taken underwent Pure Tone Audiometry (PTA) screening. Hearing was measured at $1 \mathrm{KHz}, 2$ $\mathrm{KHz}, 4 \mathrm{KHz}, 0.5 \mathrm{KHz}$ and again at $1 \mathrm{KHz}$ to ensure consistency of response and the average reading for each ear across the 4 frequencies was recorded. Children $<4$ years underwent OAE testing only. Hearing impairment was categorised as $>41 \mathrm{db}$ (adults aged $>18$ years) or $>35 \mathrm{db}$ (children $\leq 18$ years).

Depression was assessed using the Patient Health Questionnaire (PhQ-9) among participants aged $>17$ years only. This tool includes three self-reported screening questions with an additional 6 questions asked if the initial screen is positive. Depression was categorised as having a score of 20 and above (11).

\section{Self-reported functional difficulty}

The WG extended set (adult or child version) $(12,13)$ was used to screen participants for self-reported functional limitations. This includes a question on mobility which asks, for children: "Compared with children of the same age, does [name] have difficulty walking?" and for adults: "Do you have difficulty walking or climbing steps?" These questions are answered with a four-point response scale ("no difficulty", "some difficulty", "a lot of difficulty" or "cannot do at all"). The primary caregiver was interviewed as a proxy for children under the age of eight. 


\section{Training}

The survey was undertaken by three teams who underwent seven days of training. Each team consisted of two enumerators, two interviewers, one physiotherapist, one ophthalmic officer. There was also one ENT doctor who circulated between the three teams. We assessed the inter-observer variation for the determination of MSI cause and severity to ensure it was of an acceptable standard (i.e. Kappa $\geq 0.6$ ).

Data analysis

Data were analysed using STATA 14.0 (StataCorp LP, College Station, Texas). The cluster sampling design was accounted for in the prevalence estimate. We compared clinical measures of MSI to self-reported mobility difficulties through estimations of sensitivity, specificity and positive and negative predictive values. We estimated two predictive values, based on varying definitions of mobility difficulties.

\section{Ethics}

Ethical Approval was granted by Public Health Foundation of India Institutional Ethics Committee, Government of India Health Ministry Screening Committee and The London School of Hygiene \& Tropical Medicine. Informed written or finger printed consent was obtained from all participants. For children $<18$ years a caregiver was required to provide written/finger print consent and to remain present throughout the screening as per national requirements. 


\section{Results}

4,125 people were enumerated and 3,574 were screened for MSI (response rate $87 \%$ ). Of those who did not participate, $540(13.1 \%)$ were unavailable and $11(0.3 \%)$ refused. The majority $(82 \%)$ of individuals who refused were male. There was a similar distribution of males $(48 \%)$ and females $(52 \%)$ in the sample. The sample population was similar in terms of age and gender distribution to the estimates from the 2011 census for Andhra Pradesh (Table 1).

Table 1 Age and gender distribution of district (census) and study sample population

\begin{tabular}{|c|c|c|c|c|c|c|}
\hline & \multicolumn{2}{|c|}{ Males } & \multicolumn{2}{|c|}{ Females } & \multicolumn{2}{|c|}{ Total } \\
\hline $\begin{array}{l}\text { Age } \\
\text { group }\end{array}$ & $\begin{array}{c}\text { District }^{*} \\
\text { N (\%) }\end{array}$ & $\begin{array}{c}\text { Study } \\
\text { sample } \\
\text { N (\%) }\end{array}$ & $\begin{array}{c}\text { District }^{*} \\
\text { N (\%) }\end{array}$ & $\begin{array}{c}\text { Study } \\
\text { sample } \\
\text { N (\%) }\end{array}$ & $\begin{array}{c}\text { District }^{*} \\
\text { N (\%) }\end{array}$ & $\begin{array}{c}\text { Study } \\
\text { sample } \\
\text { N (\%) }\end{array}$ \\
\hline $0-9$ & $\begin{array}{c}6,996,285 \\
(16 \%)\end{array}$ & $365(21 \%)$ & $\begin{array}{c}6,592,912 \\
(17 \%) \\
\end{array}$ & $345(18 \%)$ & $\begin{array}{c}13,589,197 \\
(17 \%)\end{array}$ & $710(19 \%)$ \\
\hline $10-19$ & $\begin{array}{c}8,405,191 \\
(19 \%)\end{array}$ & $353(21 \%)$ & $\begin{array}{c}7,890,151 \\
(20 \%) \\
\end{array}$ & $320(17 \%)$ & $\begin{array}{c}16,295,342 \\
(20 \%)\end{array}$ & $673(19 \%)$ \\
\hline $20-29$ & $\begin{array}{c}7,865,584 \\
(19 \%) \\
\end{array}$ & $277(16 \%)$ & $\begin{array}{c}8,065,546 \\
(19 \%) \\
\end{array}$ & $356(19 \%)$ & $\begin{array}{c}15,931,130 \\
(19 \%)\end{array}$ & $633(18 \%)$ \\
\hline $30-39$ & $\begin{array}{c}6,498,919 \\
(16 \%)\end{array}$ & $214(13 \%)$ & $\begin{array}{c}6,592,791 \\
(15 \%) \\
\end{array}$ & $284(15 \%)$ & $\begin{array}{c}13,091,710 \\
(15 \%)\end{array}$ & $498(14 \%)$ \\
\hline $40-49$ & $\begin{array}{c}5,169,031 \\
(12 \%)\end{array}$ & $185(11 \%)$ & $4,887,711(12 \%)$ & $207(11 \%)$ & $\begin{array}{c}10,056,742 \\
(12 \%)\end{array}$ & $392(11 \%)$ \\
\hline $50-59$ & $\begin{array}{c}3,213,122 \\
(8 \%)\end{array}$ & $143(8 \%)$ & $3,353,862(8 \%)$ & $173(9 \%)$ & $\begin{array}{c}6,566,984 \\
(8 \%)\end{array}$ & $316(9 \%)$ \\
\hline $60-69$ & $\begin{array}{c}2,520,124 \\
(7 \%)\end{array}$ & $116(7 \%)$ & $2,847,567(6 \%)$ & $118(6 \%)$ & $\begin{array}{c}5,367,691 \\
(6 \%)\end{array}$ & $234(7 \%)$ \\
\hline $70-79$ & $\begin{array}{c}1,060,217 \\
(3 \%)\end{array}$ & $42(2 \%)$ & $1,096,130(3 \%)$ & $46(2 \%)$ & $\begin{array}{c}2,156,347 \\
(3 \%)\end{array}$ & $88(2 \%)$ \\
\hline $80+$ & $\begin{array}{c}325,987 \\
(1 \%)\end{array}$ & $13(1 \%)$ & $428,216(1 \%)$ & $17(1 \%)$ & $\begin{array}{c}754,203 \\
(1 \%)\end{array}$ & $30(1 \%)$ \\
\hline Total & $\begin{array}{c}42,054,460 \\
(50 \%)\end{array}$ & $\begin{array}{l}1,708 \\
(48 \%)\end{array}$ & $\begin{array}{c}41,754,886 \\
(50 \%)\end{array}$ & $\begin{array}{r}1,866 \\
(52 \%) \\
\end{array}$ & $\begin{array}{c}83,809,346 \\
(100 \%)\end{array}$ & 3,574 \\
\hline
\end{tabular}

* Census 2011 data at Andhra Pradesh State Level

\section{Prevalence of MSI}

In total, 699 participants of the 3574 screened were identified as having an MSI, giving an allage prevalence of $19.6 \%$ (95\% Cl: $16.7-22.8 \%$ ) (Table 2). The prevalence of MSI was higher among women $(21.8 \%, 18.5-25.5 \%)$ than among men $(17.1 \%, 14.2-20.4 \%)$. Prevalence of MSI increased dramatically with age, from approximately $3 \%$ in children and younger adults to $51.9 \%$ of adults over 50 years ( $95 \% \mathrm{Cl}$ : $44.7-59.1 \%$ ). Just over $80 \%$ of $\mathrm{MSI}$ cases were classified as mild (prevalence: $16.1 \%$; $95 \% \mathrm{Cl} 13.3-19.2 \%$ ), and the remainder were moderate MSI (prevalence 2.2\%; 95\% Cl 1.8-2.8\%) or severe (1.3\%; 0.9-1.8\%) (Table 2). 
Table 2- Prevalence of MSI by age, gender and impairment severity

\begin{tabular}{|c|c|c|c|c|c|c|c|c|c|c|c|c|}
\hline \multicolumn{3}{|c|}{ Total } & \multicolumn{2}{|c|}{$0-17$ years } & \multicolumn{2}{|c|}{$18-49$ years } & \multicolumn{2}{|c|}{$50+$ years } & \multicolumn{2}{|l|}{ Male } & \multicolumn{2}{|c|}{ Female } \\
\hline & $\mathbf{N}$ & $\%(95 \% \mathrm{Cl})$ & $\mathbf{N}$ & $\%(95 \% \mathrm{Cl})$ & $\mathbf{N}$ & $\%(95 \% \mathrm{Cl})$ & $\mathbf{N}$ & $\%(95 \% \mathrm{Cl})$ & $\mathbf{N}$ & $\%(95 \% \mathrm{Cl})$ & $\mathbf{N}$ & $\%(95 \% \mathrm{Cl})$ \\
\hline Any MSI & 699 & $19.6(16.7-22.8)$ & 36 & $2.9(2.0-4.4)$ & 316 & $18.8(15.0-23.3)$ & 347 & $51.9(44.7-59.1)$ & 292 & $17.1(14.2-20.4)$ & 407 & $21.8(18.5-25.5)$ \\
\hline Mild & 574 & $16.1(13.3-19.2)$ & 18 & $1.5(0.802 .6)$ & 292 & $17.4(13.8-21.7)$ & 264 & $39.5(32.8-46.7)$ & 229 & $13.4(10.7-16.6)$ & 345 & $18.5(15.3-22.2)$ \\
\hline Moderate & 80 & $2.2(1.8-2.8)$ & 11 & $0.9(0.5-1.6)$ & 16 & $1.0(0.6-1.5)$ & 53 & $7.9(5.8-10.7)$ & 41 & $2.4(1.8-3.2)$ & 39 & $2.1(1.5-2.9)$ \\
\hline Severe & 45 & $1.3(0.9-1.8)$ & 7 & $0.6(0.3-1.2)$ & 8 & $0.5(0.2-1.0)$ & 30 & $4.5(2.9-6.9)$ & 22 & $1.3(0.8-2.1)$ & 23 & $1.2(0.7-1.9)$ \\
\hline
\end{tabular}


Extrapolating these findings, we estimate that there are a total of 196000 (95\% Cl: 167000 228 000) people per million population with an MSI in this setting; 10730 (95\% Cl: 7400-16 300 ) children aged 0-17 years, 88400 (95\% Cl: 70 500-11 000) adults aged 18-50 years and 83000 (95\% Cl: $72000-95000)$ adults $>50$ years.

\section{Age of impairment}

Among children with MSI, 33\% were born with their condition and $25 \%$ acquired the impairment before they were 5 years. Among adults aged 18-50 years with $\mathrm{MSI}$, the majority $(65 \%)$ acquired their impairment during their adult years (i.e.>17 years) and only $2 \%$ were born with the impairment. Among adults aged>50 years, 95\% developed their impairment after the age of 40 years.

\section{Diagnoses}

There were a total of 741 diagnoses for 699 participants with MSI (Table 3). Of the $741 \mathrm{MSI}$ diagnosis just over half ( $n=424,57 \%$ ) were acquired non-traumatic causes, with degenerative joint disease being the most common individual diagnosis. Nearly one-third $(n=235,32 \%)$ of MSI diagnoses were acquired trauma, $9 \%(n=63)$ were neurological, $2 \%$ $(n=12)$ were due to infection and $1 \%(n=7)$ was congenital.

Table 3. MSI diagnoses in survey and extrapolated to total population of India

\begin{tabular}{|l|l|l|l|}
\hline Diagnosis & Number & $\begin{array}{l}\text { Total in } \\
\text { category } \\
\text { N (\%) }\end{array}$ & $\begin{array}{l}\text { Extrapolated total number of diagnostic } \\
\text { category to nearest } 1,000(95 \% \mathrm{Cl})\end{array}$ \\
\hline $\begin{array}{l}\text { A. Congenital } \\
\text { Polydactyly }\end{array}$ Congenital hand deformity & 1 & $7(1 \%)$ & $2,198,000(1,803,000-2,657,000)$ \\
$\begin{array}{l}\text { Congenital absence of all/part of } \\
\text { upper limb }\end{array}$ & 1 & & \\
Congenital abnormality of upper limb & 1 & & \\
Cleft lip & 2 & & \\
\hline B. Infection & & $12(2 \%)$ & $4,395,000(3,605,000-5,318,000)$ \\
Joint Infection & 8 & & \\
n/soft tissue infection/wound & 4 & & \\
\hline C. Acquired traumatic & 5 & $235(32 \%)$ & $70,319(57,683,000-85,087,000)$ \\
Burn contracture & & \\
Fracture non union & 2 & & \\
Fracture malunion & 29 & & \\
Spinal/head Injury & 9 & & \\
Post traumatic joint stiffness & 8 & & \\
Muscle problem & 167 & & \\
Peripheral nerve problem & 3 & & \\
Amputation & 7 & & \\
Other & 5 & $63(9 \%)$ & $19,778,000(16,223,000-23,931,000)$ \\
\hline D. Neurological & &
\end{tabular}




\begin{tabular}{|l|l|l|l|}
\hline Epilepsy & 17 & & \\
Developmental delay & 2 & & \\
Cerebral palsy & 5 & & \\
Paraplegia & 3 & & \\
Hemiplegia & 6 & & \\
Quadriplegia & 1 & & \\
Polio & 14 & & \\
Other neurological & 15 & $424(57 \%)$ & $125,257,000(102,747,000-151,561,000)$ \\
\hline E. Acquired non-traumatic & 291 & & \\
Degenerative joint disease & 9 & & \\
Non-infective non traumatic joint & 3 & & \\
disease & 1 & & \\
Bow legs & 55 & & \\
Knock knees & 1 & & \\
Spinal pain limiting spine function & 36 & & \\
TB/spine infection & 28 & & \\
Limb pain limiting function & & 741 & \\
Other acquired non-traumatic & 221, 947,000 (182,061,000-268,556,000) \\
Total diagnoses & The & \\
\hline Diagnoses varied by age (Figure 1). The prevalence of neurological diagnoses was similar in
\end{tabular}

Diagnoses varied by age (Figure 1). The prevalence of neurological diagnoses was similar in all age groups (Table 3). There was a proportional increase in trauma related MSI with age from $1 \%$ among $0-17$ years, $7 \%$ among $17-49$ years and $15 \%$ the $>50$ years age group. The proportion of acquired non-traumatic diagnoses also increased substantially with age so that $35 \%$ among people aged $>50$ years were acquired non-traumatic.

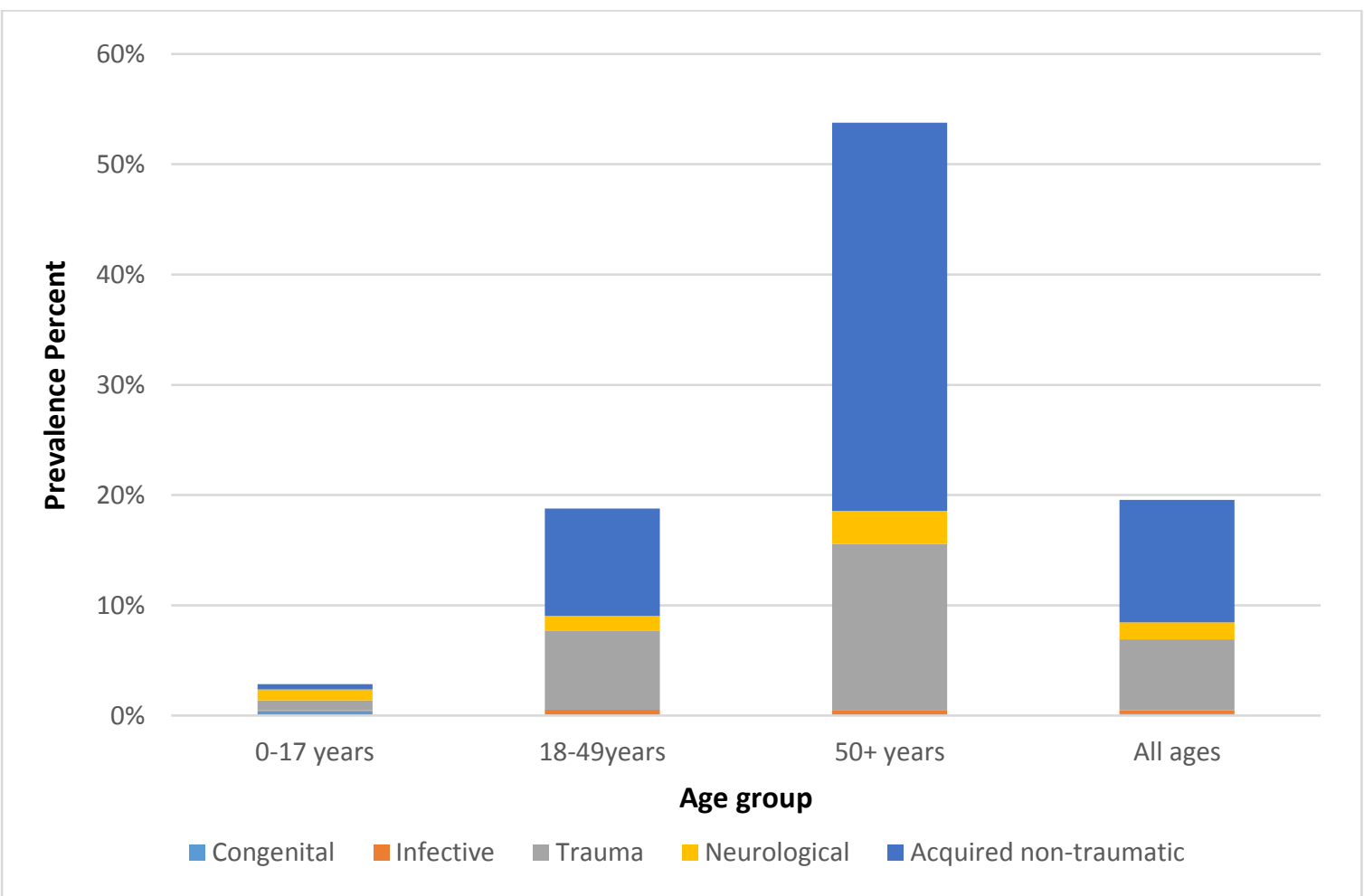

Figure 1. Prevalence and diagnostic categories of MSI by age group 


\section{Aetiology}

Of the 699 participants with MSI two-thirds $(n=450,64 \%)$ was attributed to ageing $(n=140$, $20 \%)$ or work/lifestyle $(n=310,44 \%), 12 \%(n=84)$ was due to trauma (road traffic accidents, $n=36$; violence, $n=9$; self-harm, $n=3$; and other, $n=36)$, and $4 \%(n=25)$ to congenital conditions. Other rarer aetiologies included genetic $(n=9,1 \%)$, infection $(n=21,3 \%)$, developmental $(n=14,2 \%)$ and iatrogenic $(n=2,0.3 \%)$.

Among the 36 children, the majority of MSI included congenital $(n=12,33 \%)$, other accidents $(n=7,19 \%)$ and developmental $(n=6,17 \%)$. Among 316 adults aged $18-49$ the leading aetiology was work/lifestyle $(n=215,68 \%)$ and among the 347 older adults ( $>50$ years), $40 \%$ $(n=139)$, was attributed to ageing and $32 \%(n=111)$ to work/lifestyle.

\section{Previous treatment}

The most commonly reported previous treatment or intervention received among people with MSI was medication (64\%) followed by surgery (4\%), mobility aids $(3 \%)$ and physiotherapy (3\%) (Table 4). Overall, $13 \%$ of people with MSI reported they had not previously received any medical or rehabilitation services for their condition.

Table 4 Treatment for individuals with musculoskeletal impairment

\begin{tabular}{|l|c|c|c|c|}
\hline & \multicolumn{2}{|c|}{$\begin{array}{c}\text { Treatment } \\
\text { previously } \\
\text { received }\end{array}$} & \multicolumn{2}{c|}{$\begin{array}{c}\text { Treatment } \\
\text { recommended }\end{array}$} \\
\hline & $\mathbf{N}$ & $\%$ & $\mathbf{N}$ & $\%$ \\
\hline None & 91 & $13 \%$ & 86 & $12 \%$ \\
\hline Medication & 449 & $64 \%$ & 344 & $49 \%$ \\
\hline Plaster/Splintage & 1 & $0 \%$ & 2 & $0 \%$ \\
\hline Physiotherapy & 23 & $3 \%$ & 281 & $40 \%$ \\
\hline Special Seating & 0 & $0 \%$ & 1 & $0 \%$ \\
\hline Mobility aid & 21 & $3 \%$ & 16 & $2 \%$ \\
\hline Orthosis/appliance/ Prosthesis & 3 & $0.4 \%$ & 4 & $1 \%$ \\
\hline Wheelchair & 2 & $0 \%$ & 2 & $0 \%$ \\
\hline Surgery & 25 & $4 \%$ & 21 & $3 \%$ \\
\hline Traditional medicine & 16 & $2 \%$ & 0 & $0 \%$ \\
\hline
\end{tabular}

\section{Recommended treatment}

Medical or rehabilitation services were recommended for the majority $(88 \%)$ of people with MSI in the survey. Medication was the most commonly recommended intervention $(49 \%)$ followed by physiotherapy (40\%), surgery (3\%), and mobility aids ( $2 \%)$. 
The primary reason given by participants for not seeking further treatment for MSI was inability to afford treatment (41\%), whilst $20 \%$ felt treatment was not necessary because of adequate function and 15\% felt treatment wasn't needed because of the older age.

\section{Other impairments}

Among the 699 participants identified with a MSI, 10\% (70/699) had a moderate/severe vision impairment, 11\% (77/699) had a moderate/severe hearing impairment and $3 \%$ $(21 / 699)$ moderate or worse depression. A total of $21 \%(147 / 699)$ of people with a MSI also had at least one other impairment (hearing, vision, depression). This varied by age, with $8 \%$ children $<18$ years, $4 \%$ adults $18-49$ years and $36 \%$ of adults $>50$ experiencing at least one other impairment. Restricting to those with moderate or severe $\mathrm{MSI}, 20 \%$ had vision impairment, $26 \%$ had hearing impairment, $13 \%$ were classified as having depression and overall $43 \%$ had at least one other impairment. Existence of other impairments was most common among older adults $(60 \%)$.

\section{Comparison of clinically measured MSI and self-reported difficulties with mobility}

Of the 694 people with clinically assessed MSI (mild, moderate or severe) and WG responses in the domain of "walking/climbing", 447 reported 'some' or 'more' problem with mobility (sensitivity $=64 \%$ ) using the WG questionnaire (Table 5).

Table 5: Relationship between clinically assessed impairment and self-reported difficulties with mobility

\begin{tabular}{|l|l|l|l|l|}
\hline & \multicolumn{4}{|c|}{ Self-reported difficulties } \\
\hline Clinically assessed MSI & None N (\%) & $\begin{array}{l}\text { Some N } \\
(\%)\end{array}$ & A lot N (\%) & $\begin{array}{l}\text { Extreme/ Cannot do } \\
\mathbf{N}(\%)\end{array}$ \\
\hline No MSI & $2,459(90 \%)$ & $274(10 \%)$ & $8(1 \%)$ & 0 \\
\hline Mild & $227(40 \%)$ & $307(54 \%)$ & $37(6 \%)$ & 0 \\
\hline Moderate & $16(20 \%)$ & $19(24 \%)$ & $39(49 \%)$ & $6(8 \%)$ \\
\hline Severe & $4(9 \%)$ & $8(19 \%)$ & $23(53 \%)$ & $8(19 \%)$ \\
\hline Any MSI & $247(36 \%)$ & $334(48 \%)$ & $99(14 \%)$ & $14(2 \%)$ \\
\hline
\end{tabular}

*NB: WG data were missing for 19 people

Of the 2,741 people who did not have an MSI according to the clinical assessment, 2,459 reported no difficulty with mobility (specificity: $90 \%$ ). Of the 2,712 who reported no difficulty, 2,459 also had no MSI (negative predictive value: 91\%). Among the 729 who reported 'some' or 'more' difficulty, only 447 had a clinically assessed MSI (positive predictive value: $61 \%$ ). If a narrower self-reported definition of 'a lot of difficulty' or greater is used, the sensitivity decreased to $16 \%$, specificity increased to $100 \%$, and positive and negative predictive values were $93 \%$ and $83 \%$ respectively. 


\section{Discussion}

This all age population-based survey found a high prevalence of MSI in Mahabubnagar District India with nearly a fifth of the population affected. The majority $(82 \%)$ of MSI cases were classified as mild, $11 \%$ as moderate and $7 \%$ as severe. The prevalence of MSI increased dramatically with age, from $3 \%$ in children to $51 \%$ among people aged $>50$ years. This is due to the increase in MSI from acquired non-traumatic causes (particularly degenerative joint diseases) and trauma occurring in this older age group. There is a large unmet need for rehabilitation and treatment.

\section{Comparison to previous studies}

There are limited data from India to compare our findings. Our estimates are considerably higher than the $2.2 \%$ prevalence of all disability estimated in the 2011 census (14). However, the census used a single question on self-reported disability ('Is this person mentally/physically disabled?) which is likely to lead to under-reporting of disability because of issues around stigma and self-identification of disability (5). The high prevalence of MSI among older adults aligns with a previous study in the city of Chandigarh which reported that $88 \%$ of elderly people (aged over 60 years) had minimal to severe disabilities (15). Data on MSI epidemiology specifically are lacking, but the high prevalence in our survey concurs with a study in southern India which found that $26 \%$ of adults (>15 years) reported musculoskeletal pain (16). Our prevalence estimates (19.6\%) were higher than previous surveys using the RAM survey in Rwanda (5.2\%)(7) and Cameroon (11.6\%) (8), although the trend of rapidly increasing prevalence by age and distribution of causes were similar. The difference is driven primarily by a higher prevalence of mild MSI in India (16.1\%) compared to Cameroon (8.2\%) and Rwanda (2.4\%). The prevalence for moderate/severe MSI in the three settings is comparable (India 3.5\%, Cameroon 3.4\%, Rwanda 2.8\%). A reason for this may include the higher life expectancy in India (68.5 years versus 58.5 years in Cameroon and 60.1 years in Rwanda)(16) or the inclusion of a question on back pain in India, but not in the other settings.

\section{Treatment gap}

Most people with $\mathrm{MSI}(87 \%)$ reported having received some kind of medical or rehabilitation services, however, this was most commonly medication (64\%), which could include painkillers. The proportion that received physiotherapy was very low $(3 \%)$ and yet this was recommended as an intervention for $40 \%$ of cases based on clinical examination. This treatment gap is similar to previous studies in India that demonstrated few persons with disabilities benefit from rehabilitation services (17) and providing rehabilitation services to the 
unreached persons with disabilities living in rural areas and small towns is a challenge (18). The finding in our study that cost was the leading reason for not seeking services, aligns with research in Uttar Pradesh and Tamil Nadu states of India (19). These studies also found lack of services and transportation were key barriers to using health facilities. Additionally, there is a need to think beyond the provision of rehabilitation toward holistic inclusion of persons with disabilities. Participation of persons with disabilities may be encouraged through communitybased rehabilitation (CBR) programmes in rural communities. For example, a three-year project in a disadvantaged community near Allahabad, India, resulted in many children with disabilities attending school for the first time, and more carers bringing their children with disabilities for vaccination and rehabilitation (20).

\section{Relationship between clinically assessed and self-reported MSI}

Previous surveys typically either assessed only self-reported limitations in physical functioning (e.g. difficulty with walking) or, a few, conduct clinical assessment of MSI. In this study we collected data using both approaches, which allowed us to explore the overlap between the populations identified by the two methods. Using self-report of 'some' or 'more' difficulty' with walking/climbing would result in $36 \%$ of mild or worse MSI not being identified. Using the narrower category of 'a lot of difficulty' (the definition commonly used in surveys for classifying people as having a disability (5) would miss $39 \%$ of the clinically confirmed cases with moderate or worse MSI or $86 \%$ with mild or worse MSI. Further, $61 \%$ of those who self-reported 'some' or 'more' difficulty were not classified as having an impairment. The discrepancies in population identified suggests that the two measurement approaches capture different aspects of disability. The RAM method uses self-report functioning questions to screen in the first stage and asks a greater number of specific questions on body function, as well as whether any body parts are considered misshapen. The WG questions focus on walking/climbing only and this may explain the difference. Using clinical assessment and self-report together in disability surveys may be helpful to identify the majority of people with disability (5), although a focus on clinical assessment may be optimal when planning need for physical rehabilitation services.

\section{Recommendations}

The data collected in this survey provide useful information to assist planning of rehabilitation services for persons with MSI in India, which cannot be produced through self-reported functional difficulties alone. This study estimates that 196,000 people per million population in India will experience MSI, that degenerative joint diseases are the leading cause and that the vast majority could benefit from some kind of medical or rehabilitation intervention. Production and supply for equipment (e.g. assistive devices) can be anticipated and the need 
for services such as physiotherapy and surgery as well as equipment can be similarly estimated. For example, findings suggest that $44,390,000$ people in India could benefit from Physiotherapy. This global gap in resources has been recognised by the World Health Organisation (WHO) with the Rehabilitation 2030: A Call for Action (21). As provision of rehabilitation grows as an international priority in order to meet the Universal Health Coverage targets, plans that account for the growth of non-communicable diseases and for an ageing population are required. Scale up of rehabilitation services and consideration of innovative methods to provide rehabilitation and other services, such as mobile tools for home exercise programmes (22) warrant further investigation. In addition, the survey data highlight that experiencing multiple impairments is common. This should be taken into account when planning services to ensure, for example, that physiotherapy services are fully accessible to those with vision or hearing impairments and that appropriate attention and support is given to the psychological well-being of people with physical impairments.

\section{Strengths and limitations}

This was an all-age population based survey that used robust sampling methodology to provide estimates of musculoskeletal impairment and rehabilitation needs. There are some study limitations. The study relied on a relatively simplified assessment that was conducted in the field rather than in clinical settings. Unlike vision or hearing which have objective tests, classifying the severity of MSI is in part down to the clinician's judgement and therefore some subjectivity in this assessment is unavoidable. We aimed to standardise this as much as possible with thorough training of the physiotherapists.

\section{Conclusions}

Nearly a fifth of people living in Mahabubnagar District have a musculoskeletal impairment and this is estimated to be moderate or severe for $3.5 \%$. Among adults aged 50 years and above the prevalence was $51 \%$ and this was largely due to degenerative joint diseases. The findings suggest there is high unmet need for physiotherapy and other rehabilitation services among people with MSI.

\section{Authors' statements}

Authors' contributions: HK conceived the study; HK SP and IM designed the study protocol; IM SP and TS carried out the analysis and interpretation of these data. TS and SP drafted the manuscript; IM HK GM and CL critically revised the manuscript for intellectual content. All authors read and approved the final manuscript. TS and SP are guarantors of the paper. Funding: This work was supported by CBM The authors declare no competing interests 
Ethical approval: Ethical Approval for the study was granted by Indian Institute of Public Health, Hyderabad, India Institutional Ethics Committee, Government of India Health Ministry Screening Committee and The London School of Hygiene \& Tropical Medicine. 


\section{References}

1. Collaborators GBoD. Global, regional, and national incidence, prevalence, and years lived with disability for 310 diseases and injuries, 1990-2015: a systematic analysis for the Global Burden of Disease Study 2015. Lancet. 2016;388(10053):1545-602.

2. Banks L, Polack S. The economic costs of exclusion and gains of inclusion of people with disabilities: Evidence from low and middle income countries. London School of Hygiene and Tropical Medicine, 2014.

3. Banks LM, Mearkle R, Mactaggart I, Walsham M, Kuper H, Blanchet K. Disability and social protection programmes in low- and middle-income countries: a systematic review. Oxford Development Studies. 2016:1-17.

4. WHO. World Report on Disability. 2011.

5. Mactaggart I, Kuper H, Murthy GV, Oye J, Polack S. Measuring Disability in Population Based Surveys: The Interrelationship between Clinical Impairments and Reported Functional Limitations in Cameroon and India. PLoS One. 2016;11(10):e0164470.

6. Atijosan O, Kuper H, Rischewski D, Simms V, Lavy C. Musculoskeletal impairment survey in Rwanda: design of survey tool, survey methodology, and results of the pilot study (a cross sectional survey). BMC Musculoskelet Disord. 2007;8:30.

7. Atijosan $O$, Rischewski D, Simms V, Kuper H, Linganwa B, Nuhi A, et al. A national survey of musculoskeletal impairment in Rwanda: prevalence, causes and service implications. PLoS One. 2008;3(7):e2851.

8. Smythe T, Mactaggart I, Kuper H, Oye J, Sieyen NC, Lavy C, et al. Prevalence and causes of musculoskeletal impairment in Fundong District, North West Cameroon: Results of a population based survey. Tropical Medicine \& International Health.n/a-n/a.

9. Mactaggart I, Kuper H, Murthy GV, Sagar J, Oye J, Polack S. Assessing health and rehabilitation needs of people with disabilities in Cameroon and India. Disabil Rehabil. 2016;38(18):1757-64.

10. Technical Report Series. WHO. The burden of musculoskeletal conditions at the start of the new millenium. Geneva: 2003.

11. Lowe B, Kroenke K, Herzog W, Grafe K. Measuring depression outcome with a brief selfreport instrument: sensitivity to change of the Patient Health Questionnaire (PHQ-9). J Affect Disord. 2004;81(1):61-6.

12. Madans JH, Loeb ME, Altman BM. Measuring disability and monitoring the UN Convention on the Rights of Persons with Disabilities: the work of the Washington Group on Disability Statistics. BMC Public Health. 2011;11 Suppl 4(4):S4.

13. Altman BM, Rasch EK. Purpose of an International Comparable Census Disability Measure. In: Altman BM, editor. International Measurement of Disability: Purpose, Method and Application. Cham: Springer International Publishing; 2016. p. 55-68.

14. Office of the Registrar General and Census Commissioner I. Census of India 2011. 2011.

15. Joshi K, Kumar R, Avasthi A. Morbidity profile and its relationship with disability and psychological distress among elderly people in Northern India. International Journal of Epidemiology. 2003;32(6):978-87.

16. Mathew AJ, Chopra A, Thekkemuriyil DV, George E, Goyal V, Nair JB. Impact of musculoskeletal pain on physical function and health-related quality of life in a rural community in south India: A WHO-ILAR-COPCORD-BJD India Study. Clinical Rheumatology. 2011;30(11):1491.

17. Kumar SG, Das A, Soans SJ. Quality of rehabilitation services to disabled in a rural community of karnataka. Indian J Community Med. 2008;33(3):198-200.

18. Kumar SG, Roy G, Kar SS. Disability and Rehabilitation Services in India: Issues and Challenges. Journal of Family Medicine and Primary Care. 2012;1(1):69-73.

19. Bank W. People with disabilities in India: from commitments to outcomes Washington2009. Available from: (http://www-wds.world- 
bank.org/external/default/WDSContentServer/WDSP/IB/2009/09/02/000334955 20090902041543/ Rendered/PDF/502090WPOPeopl1Box0342042B01PUBLIC1.pdf, accessed, 13 October 2016.

20. Dalal AK. Social interventions to moderate discriminatory attitudes: the case of the physically challenged in India. Psychol Health Med. 2006;11(3):374-82.

21. Gimigliano F, Negrini S. The World Health Organization "Rehabilitation 2030: a call for action". Eur J Phys Rehabil Med. 2017;53(2):155-68.

22. Sureshkumar K, Murthy GV, Munuswamy S, Goenka S, Kuper H. 'Care for Stroke', a webbased, smartphone-enabled educational intervention for management of physical disabilities following stroke: feasibility in the Indian context. BMJ Innov. 2015;1(3):127-36. 